\title{
Implementation of Affective States and Learning Styles Tactics in Web-based Learning Management Systems
}

\author{
Farman Ali Khan ${ }^{1}$, Sabine Graf ${ }^{2}$, Edgar R. Weippl ${ }^{1}$, A Min Tjoa ${ }^{1}$ \\ ${ }^{1}$ Institute of Software Technology and Interactive Systems, Vienna University of Technology, Austria \\ ${ }^{2}$ School of Computing and Information Systems, Athabasca University, Canada \\ farman@ifs.tuwien.ac.at, sabineg@athabascau.ca,weippl@securityresearch.at, tjoa@ifs.tuwien.ac.at
}

\begin{abstract}
Learning styles and affective states have a significant effect on student learning. The aim of this paper is to present a concept to identify and integrate learning styles and affective states of a learner into web-based learning management systems and therefore providing learners with adaptive courses and additional individualized pedagogical guidance that is tailored to their learning styles and affective states. Through considering affective states and learning styles, learners are provided with a learning environment that is more personalized and tailored to learners needs and current situation, leading to better learning outcomes and progress.
\end{abstract}

Keywords-Adaptivity, Student Modeling, Learning Management Systems, Affective States, Learning Styles

\section{INTRODUCTION}

The possibility to provide personalize web-based courses based on student's learning requirements and methodological preference is an interesting open research area with large application perspective [1]. Presently, the structure and the pedagogical material of web-based courses are usually statically defined by web learning designers (or by teachers). Most of the currently used learning systems cannot take into account the students' preferred ways of learning as well as their learning behavior. On the other hand, modern pedagogical theories and research/models emphasize to personalize the course material, in order to enhance the students' learning $[1,2]$.

Furthermore, despite the importance of affective states in learning, this crucial parameter seems to have been ignored, in most web-based learning systems [3]. This omission of affective states deprives the education from a very important pedagogical dimension.

Thus, there is a need to turn the attention to identify students' learning style and affective states that influence learning, and combining them in order to provide personalized courses for learners that consider their learning styles and affective states, leading to the achievement of a milestone of delivering personalized e-learning courses in learning management systems and therefore broaden the provision of adaptivity and personalization in commonly used learning systems.

In this paper, we propose an automatic student modeling approach for identifying learning styles and affective states in web-based learning management systems (LMSs). Based on the gathered information about students' characteristics, adaptive course generation as well as adaptive guidance is provided by the LMS.

\section{The ARCHITECTURE OF AN AfFECTIVE STATES AND LEARNING STYLE MODULE}

The "Affective States and Learning Style" module (ALSM) aims to recognize the students' learning styles (LS) and affective states (AS) during students' interactions in a web-based learning management system environment and thereafter to provide students with a suitable learning strategy. The suitable learning strategy is adaptive in nature and realized through an adaptive course generator (ACG) and an adaptive affective tactic generator (AATG).

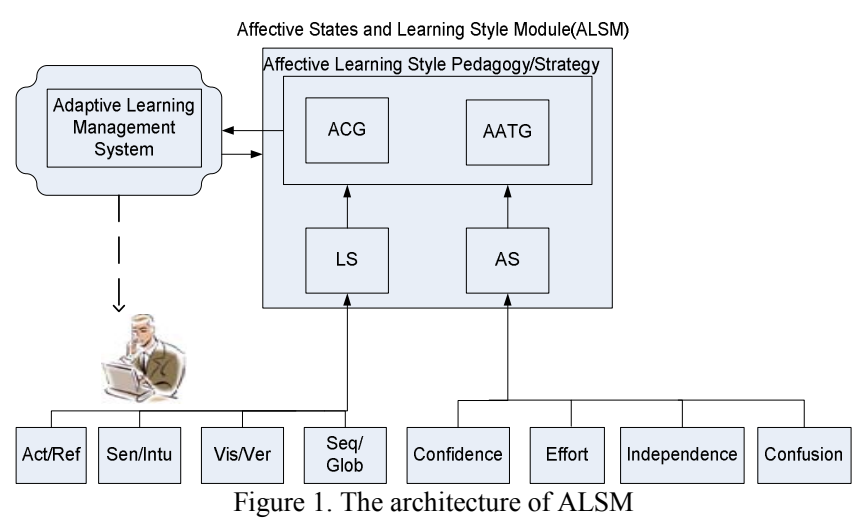

The module is being attached to a learning management system providing the system with the essential "learning style and affective state" information in order to determine the learning strategy presented to the learner. The main purpose of ALSM is to create an appropriate learning environment for students, taking into account particular affective states in combination with learning styles and offering personalized learning that considers both of these students' characteristics.

\section{A. Recognizing the Learning Styles and Affective States of Students}

For the students' learning style recognition in a webbased educational system currently questionnaires, self 
reports and automatic approaches are used. Similarly for the affective state recognition verbal (questionnaire, self report), nonverbal (heart rate, blood pressure, and skin conductance etc.), intrusive (speech, facial expression, and gestures), and nonintrusive (automatic) approaches are used. The benefit of automatic approaches whether it is used for learning style or affective state recognition is that it is free from uncertainty as it avoids students' involvement in providing explicit feedback about their preferences.

Concerning the ALSM, a core part of the module is the recognition of the students' learning styles in the LS component and students' affective state in the AS component. The LS component (Figure 1) is composed by four subcomponents which are responsible for identifying, storing and frequently updating information about the four learning style dimensions pointed out by Felder and Silverman [4]. Similarly, the AS component (Figure 1) is composed by four subcomponents, which are responsible for particular affective states. Those particular affective states have been identified from a set of affective states to be relevant and important for learning [5], [6].

Learning styles and affective states information are gathered from students' interactions in a web-based learning management system. The LS and AS components monitor the students' behavior on features that are commonly used in web-based LMSs. Those commonly used features include content objects, outlines, exercises, self assessment tests, examples, discussion forums for assignment related queries, discussion/peer rating forums related to the content objects, and assignments. Considering information from all these features, the LS and AS components identify the students' learning styles as well as affective states using a rule- based approach.

\section{B. Providing Students with the Learning Style based appropriate Affective Tactic}

After being recognized by the respective components, the students' learning styles and affective states are used by the affective learning style pedagogy component for two purposes. The first purpose deals with adaptive sequencing and annotating of the course/educational material according to students' learning styles. This purpose is accomplished by the ACG component using the available learning style information for generating an adaptive course based on the available learning material and activities. The second purpose is about the adaptive selection and presentation of additional elements from the AATG repository when a student's affective state is identified to be below average and therefore indicates that the student is experiencing learning difficulties. This purpose is accomplished by the AATG component using the available affective state information in collaboration with the available learning style information in order to provide students with chunks of information that help them in their current situation. The AATG repository contains elements such as Definitions, Pictures, Applications, Examples, Relationships, Scaffolds, Exercises, and Questions for additional pedagogical guidance of students. The AATG component selects and presents those elements for pedagogical guidance that fit best students' learning styles according to the learning style dimensions of the Felder-Silverman learning style model [4]. The mapping between learning styles and suitable pedagogical guidance is based on recommendations from [7]. The ACG and AATG are introduced to facilitate students' learning by considering not only their learning styles but their affective states as well.

\section{CONCLUSION}

In this paper, we introduced the affective states and learning style module which helps to bring adaptivity based on learning styles and affective states into web-based learning management systems. This enhanced module relies on an automatic approach for identifying learning styles and affective states from students' interaction with the system. The gathered information is then used to provide the student with the appropriate, pedagogical material and guidance.

\section{ACKNOWLEDGMENTS}

Authors acknowledge the support of NSERC, iCORE, Xerox, and the research related gift funding by $\mathrm{Mr}$. A. Markin.

\section{REFERENCES}

[1] E. Sangineto, N. Capuano, M. Gaeta and A. Micarelli, "Adaptive course generation through learning styles representation", Journal of Universal Access in the Information Society 7(1), 1-23 (2008).

[2] M. Siadaty and F. Taghiyareh, "PALS2: Pedagogically Adaptive Learning System based on Learning Styles," icalt, pp.616-618, Seventh IEEE International Conference on Advanced Learning Technologies (ICALT 2007), 2007

[3] M. Leontidis, C. Halatsis and M. Grigoriadou, "e-Learning Issues Under an Affective Perspective", In: Li, F., Zhao, J., Shih, T.K., Lau, R., Li, Q., McLeod, D. (eds.) ICWL 2008.LNCS, vol. 5145, pp. 27 38. Springer, Heidelberg (2008)

[4] R.M. Felder and L.K. Silverman, Learning and teaching styles in engineering education, Engineering Education, 78(7), pp. 674-681, 1988.

[5] L. Qu, N. Wang and W. Lewis Johnson, "Using Learner Focus of Attention to Detect Learner Motivation Factors", In Ardissono, L., Brna, P., Mitrovic, A.: User Modelling 2005, pp 70-73

[6] A. De Vicente H. Pain, "Informing the Detection of the Students' Motivational State: An Empirical Study", Proceedings of the Sixth International Conference on Intelligent Tutoring Systems, pp 933943, 2002.

[7] S. M. Parvez. A Pedagogical Framework for Integrating Individual Learning Style into an Intelligent Tutoring System. Ph.D Thesis, Lehigh University, 2007 